\title{
DESCRIPTION AND INTERCOMPARISON OF TECHNIQUES TO MEASURE N AND S COMPOUNDS IN THE WESTERN ATLANTIC OCEAN EXPERIMENT
}

\author{
Donald R. Hastie and Harold I. Schiff \\ Chemistry Department, York University, Keele Street, North York, Ontario, Canada M3J IP3 \\ Douglas M. WhelPDale \\ Atmospheric Environment Service, 4905 Dufferin Street, Downsview, Ontario, Canada M3H 5T4 \\ Richard E. Peterson and William H. Zoller \\ Chemistry Department, University of Washington, Seattle. WA 98195, U.S.A. \\ David L. ANDERson \\ Department of Chemistry and Biochemistry, University of Maryland, College Park, MD 20742, U.S.A. \\ and \\ Thomas M. Church \\ College of Marine Studies. University of Delaware, Newark, DE 19711, U.S.A.

\begin{abstract}
Abetract-The data set of $\mathrm{N}$ and $\mathrm{S}$ compound measurements from WATOX-85 has been examined in detail to assess that data quality and suitability for use in addressing the goals of the Western Atlantic Oocan Experiment. Accuracy estimates for particulate $\mathrm{SO}_{4}^{2-}$ and $\mathrm{NO}_{3}^{-}, \mathrm{SO}_{2}$ and $\mathrm{HNO}_{3}$ have been made on the basis of the investigators' estimates and the results of intercomparisons. Intercomparisons of ground-based particulate $\mathrm{SO}_{4}^{2-}$ and all filter $\mathrm{SO}_{2}$ and $\mathrm{HNO}_{3}$ measurements show them to be consistent with the $20 \%$ accuracies quoted by the investigators. Ground-based particulate $\mathrm{NO}_{3}^{-}$and aircraft particulate $\mathrm{SO}_{4}^{2-}$ show inconsistencies such that the accuracies can be no better than $28 \%$ and the aircraft particulate $\mathrm{NO}_{3}^{-}$has an accuracy of no better than $60 \%$.
\end{abstract}

Key word index: WATOX, Atlantic Ocean, sulphur, nitrogen, measurement techniques.

\section{INTRODUCTION}

The Western Atlantic Ocean Experiment (WATOX) aims to determine the flux and fate of a number of chemical species that are advected eastward from North America. Of primary interest are the sulphur and nitrogen oxides from anthropogenic sources.

The field measurement program of WATOX has two components, long-term and intensive. The longterm phase gathers continuous data of the composition of wet deposition at Lewes, Delaware, Bermuda and Ireland. These data are used to determine the wet deposition flux to the North Atlantic and to trace air masses from North America. Intensives are held on an occasional basis to investigate the processes that control the transport, transformation and deposition of materials to the Western Atlantic Ocean. A major WATOX intensive was mounted from 15 February to 30 March 1985. During this intensive, measurements of NO, NO' (nitrogen oxides as measured with a
$\mathrm{FeSO}_{4}$ converter), $\mathrm{HNO}_{3}, \mathrm{SO}_{2}, \mathrm{O}_{3}$, particulate $\mathrm{SO}_{4}^{2-}$ and particulate $\mathrm{NO}_{3}^{-}$were made at ground stations at Lewes, Delaware, and Bermuda, and from an aircraft. A total of seven groups, operating a wide range of instrumentation and using several different analytical techniques, were involved.

In this type of program one must take steps to ensure that each data set is reliable and that the various sets, taken at different sites, are intercomparable. The optimum procedure for ensuring data integrity is to run a formal intercomparison prior to the measurement campaign where all systems measuring the same species are run side by side in a double-blind experiment so any anomalies can be immediately identified. After such an intercomparison the instrument systems can be dispatched to the field sites and one can be confident of the data quality. Such a formal intercomparison was not possible for this program. There was, however, a large degree of duplication in the measurements, with more than one system 
measuring the same species at the same site. We have used these overlapping data to estimate the quality of the overall data set generated by the WATOX -85 intensive.

The conclusions that can be drawn from this process depend on the species being measured. An estimate of the accuracy of the $\mathrm{HNO}_{3}$ measurements can be made as there are three systems using two techniques, one of which provides a direct $\mathrm{HNO}_{3}$ measurement. However, $\mathrm{SO}_{4}^{2-}$ and $\mathrm{NO}_{3}^{-}$measurements are made with identical systerns so accuracy assessments are not possible. The best one can do is pinpoint inconsistencies between systems. Furthermore, the small number of samples limits the ability to use the standard deviation as a true measure of the precision of the measurement techniques.

\section{SITES AND MEASUREMENT TECHNIQUES}

A ground site at Lewes, Delaware, was used to characterize air masses leaving North America, while a site at Bermuda was used to characterize mid-ocean air masses. The horizontal and vertical variation of the target species was determined by use of an aircraft. The Lewes site was in an open area approximately
$150 \mathrm{~m}$ south of the MAP3S precipitation collection site in the Cape Henlopen State Park. It is described in more detail in Wolff et al. (1986). The ocean site was on the western end of the island of Bermuda at High Point, on a $35 \mathrm{~m}$ sea cliff on the south shore. With the prevailing westerly flow at this time of year, samples were little influenced by the island itself.

Aircraft measurements were made from the NOAA Air Quality Division's Beechcraft King Air C-90. This aircraft has a payload weight of $1620 \mathrm{~kg}$ including fuel, a cruising speed of $113 \mathrm{~ms}^{-1}$, although this was lowered to $55 \mathrm{~m} \mathrm{~s}^{-1}$ for sampling in this program, and a flight duration of $5 \mathrm{~h}$.

Table 1 gives a summary of the species of interest that were measured at each of the three sites, broken down by group and analytical technique. A brief description of each of the measurement techniques is given below.

The University of Maryland : University of Washington (UMD:UW) multiple-filter system is described in detail by Kitto et al. (1988). It consists of five stacked but separated $110 \mathrm{~mm}$ filters, the first being a Teflonbased (Zefiuor or Fluoropore) particulate filter, followed by four ${ }^{7} \mathrm{LiOH}$-glycerol-treated Whatman-41 filters for trapping acidic gases. Flow rates of several $\ell \mathrm{s}^{-1}$ were achieved giving total daily sample volumes

Table 1. Instrumentation operational during the WATOX'85 INTENSIVE

\begin{tabular}{|c|c|c|c|}
\hline Species & Site & Group & $\begin{array}{l}\text { Instrument/ } \\
\text { analytical technique }\end{array}$ \\
\hline Particulate sulphate & $\begin{array}{l}\text { Lewes } \\
\text { Bermuda } \\
\text { Aircraft }\end{array}$ & $\begin{array}{l}\text { AES } \\
\text { UMD:UW } \\
\text { AES } \\
\text { UMD:UW } \\
\text { AES } \\
\text { UMD:UW }\end{array}$ & $\begin{array}{l}\text { Filter pack/I.C.* } \\
\text { Filter pack/I.C. } \\
\text { Filter pack/I.C. } \\
\text { Filter pack/I.C. } \\
\text { Filter pack/I.C. } \\
\text { Filter pack/I.C. }\end{array}$ \\
\hline Particulate nitrate & $\begin{array}{l}\text { Lewes } \\
\text { Bermuda } \\
\text { Aircraft }\end{array}$ & $\begin{array}{l}\text { AES } \\
\text { UMD:UW } \\
\text { AES } \\
\text { UMD:UW } \\
\text { AES } \\
\text { UMD:UW }\end{array}$ & $\begin{array}{l}\text { Filter pack/I.C. } \\
\text { Filter pack/I.C. } \\
\text { Filter pack/I.C. } \\
\text { Filter pack/I.C. } \\
\text { Filter pack/I.C. } \\
\text { Filter pack/I.C. }\end{array}$ \\
\hline $\mathrm{NO}_{x}^{\prime}$ & $\begin{array}{l}\text { Lewes } \\
\text { Bermuda } \\
\text { Aircraft }\end{array}$ & $\begin{array}{l}\text { York/Unisearch } \\
\text { None } \\
\text { York/Unisearch }\end{array}$ & $\begin{array}{l}\text { Chemiluminescence } \\
\text { Chemiluminescence }\end{array}$ \\
\hline Nitric acid & $\begin{array}{l}\text { Lewes } \\
\text { Bermuda } \\
\text { Aircraft }\end{array}$ & $\begin{array}{l}\text { AES } \\
\text { UMD:UW } \\
\text { York/Unisearch } \\
\text { AES } \\
\text { UMD:UW } \\
\text { AES }\end{array}$ & $\begin{array}{l}\text { Filter pack/I.C. } \\
\text { Filter pack/I.C. } \\
\text { Tunable Diode Laser } \\
\text { Filter pack/I.C. } \\
\text { Filter pack/I.C. } \\
\text { Filter pack/I.C. }\end{array}$ \\
\hline Sulphur dioxide & $\begin{array}{l}\text { Lewes } \\
\text { Bermuda } \\
\text { Aircraft }\end{array}$ & $\begin{array}{l}\text { AES } \\
\text { UMD:UW } \\
\text { AES } \\
\text { UMD:UW } \\
\text { AES } \\
\text { NOAA }\end{array}$ & $\begin{array}{l}\text { Filter pack/l.C. } \\
\text { Filter pack/I.C./PGAA } \\
\text { Filter pack/I.C. } \dagger \\
\text { Filter pack/I.C. } \\
\text { Filter pack/I.C. } \\
\text { Flame Photometric }\end{array}$ \\
\hline Ozone & $\begin{array}{l}\text { Lewes } \\
\text { Bermuda } \\
\text { Aircraft }\end{array}$ & $\begin{array}{l}\text { York/Unisearch } \\
\text { None } \\
\text { NOAA }\end{array}$ & $\begin{array}{l}\text { u.v. absorption } \\
\text { u.v. absorption }\end{array}$ \\
\hline
\end{tabular}

\footnotetext{
*IC - ion chromatography, †PGAA-prompt gamma activation analysis.
} 
of hundreds of $\mathrm{m}^{3}$. Filters were sealed in plastic bags and shipped to the laboratory for analysis. In most cases particulate $\mathrm{SO}_{4}^{2-}$ and $\mathrm{NO}_{3}^{-}$from the Tefion filter, and $\mathrm{SO}_{2}$ and $\mathrm{HNO}_{3}$ on the basic filters were measured by ion chromatography (IC) at the University of Washington. For many of the basic filters neutron capture prompt $\gamma$-activation analysis (PGAA) (Germani et al., 1980) was used to determine S, which was assumed to be entirely due to $\mathrm{SO}_{2}$. Irradiations were performed at the National Bureau of Standards Reactor in Gaithersburg, Maryland. It was not possible to do complete double analyses for $\mathrm{S}$ so the $\mathrm{SO}_{2}$ data are a mix of PGAA and IC data. The Bermuda data are from ion chromatography only, whereas the Lewes data are a mix of PGAA and IC. The data were supplied with measurement error estimates for each individual measurement. All measurements were well above detection limits. For the purposes of this intercomparison these errors have been divided into a precision (10\%) and an instrumental accuracy (20\%).

The triple filterpack system of the Atmospheric Environment Service (AES) has been described in detail by Anlauf et al. (1985). The system consists of three $47 \mathrm{~mm}$ diameter filters separated within a single Teflon housing. The first is a $1 \mu \mathrm{m}$ pore size Teflon filter (Membrana Corp.) for trapping particles; the second is a $1 \mu \mathrm{m}$ pore size nylon filter (Membrana Corp.) for trapping $\mathrm{HNO}_{3}$; and the third is a Whatman-41 filter, impregnated with an aqueous solution of $10 \% \mathrm{v} / \mathrm{v}$ glycerol and $25 \% \mathrm{w} / \mathrm{v}$ potassium carbonate for trapping gaseous $\mathrm{SO}_{2}$. Air was sampled at a rate of approximately $25 \ell \mathrm{min}^{-1}$ and measured by a mass flowmeter. Exposed filters were stored individually in glass vials and shipped to AES for chemical extraction and chromatographic analysis as described in Anlauf et al. (1985). A precision of $10 \%$ and an accuracy of better than $20 \%$ for all species is quoted in Anlauf et al. (1985). The detection limit is a function of the sample volume and the blank mass and can vary markedly. Typical detection limits for the groundbased systems were: $4 \mathrm{nmol} \mathrm{m}^{-3}(0.08 \mathrm{ppbv})$ for $\mathrm{HNO}_{3} ; \quad 6 \mathrm{nmol} \mathrm{m}^{-3} \quad\left(0.5 \mu \mathrm{g} \mathrm{m}^{-3}\right)$ for $\mathrm{SO}_{4}^{2-}$; $10 \mathrm{nmol} \mathrm{m}^{-3}\left(0.6 \mu \mathrm{g} \mathrm{m}^{-3}\right)$ for $\mathrm{NO}_{3}^{-}$and $8 \mathrm{nmol} \mathrm{m}^{-3}$ $(0.2 \mathrm{ppbv})$ for $\mathrm{SO}_{2}$. Detection limits on the aircraft were sometimes as much as $\mathbf{1 0}$ times these limits.

Nitrogen oxides were measured in real time by the York/Unisearch group using two York-Scintrex chemiluminescence analyzers equipped with ferrous sulphate converters (Misanchuk et al., 1987). These instruments measure NO by detecting the chemiluminescence of $\mathrm{NO}_{2}$ that results when the NO in the air is reacted with a large excess of $\mathrm{O}_{3}$ within the instrument. NO ${ }_{x}^{\prime}$ is measured by chemical conversion to NO by ferrous sulphate, prior to reaction with ozone. Fehsenfeld et al. (1987) have shown $\mathrm{NO}_{x}^{\prime}$ to be the sum of NO and $\mathrm{NO}_{2}$ with contributions from other nitrates, particularly PAN. On a $1-s$ average the detection limit was $100 \mathrm{ppt}$ for $\mathrm{NO}$ and $\mathrm{NO}_{x}^{\prime}$; signal averaging further lowered this to $50 \mathrm{ppt}$. Calibration was performed by standard addition of Airco standards of $\mathbf{N O}$ in $\mathbf{N}_{2}$ which were characterized by the manufacturer. The aircraft standard was calibrated before and after the mission, but the Lewes cylinder was inadvertently emptied before recalibration so that the accuracy of these data is not as high as that on the aircraft. The precision of the two instruments is $10 \%$; the accuracy of the aircraft data set is $\pm 20 \%$ and the Lewes data set $\pm 30 \%$.

Ozone was measured in real-time by a Dasibi Model 1003-AH u.v. absorption instrument. This instrument had been, calibrated against Ontario Ministry of the Environment standards prior to the mission. The manufacturer quotes an accuracy of 3 ppbv or $3 \%$, whichever is greater.

Nitric acid and formaldehyde were measured in real time at the Lewes site by a Tunable Diode Laser Absorption Spectrometer similar to that described in Hastie et al. (1983). $\mathrm{HNO}_{3}$ was measured in the $1680 \mathrm{~cm}^{-1}$ region and calibrated by standard addition of known concentrations of $\mathrm{HNO}_{3}$ from a permeation device. The calibration system is described in full in Anlauf et al. (1985). The precision of the technique is $10 \%$ and the accuracy of the $\mathrm{HNO}_{3}$ measurements is $\pm 20 \%$ for values above the detection limit of $5 \mathrm{nmol} \mathrm{m}^{-3}$ (0.1 ppbv).

The NOAA King Air aircraft has a standard complement of instrumentation which includes temperature, humidity, wind speed, wind direction, position, altitude, and particulate concentration and size-distribution. For this mission NOAA supplemented this package with $\mathrm{O}_{3}$ and $\mathrm{SO}_{2}$ instruments. $\mathrm{O}_{3}$ was measured with an unmodified Dasibi Model 1003-AH u.v. absorption instrument whose output was pressure corrected post-flight. This instrument was calibrated against a standard after the campaign. $\mathrm{SO}_{2}$ was measured with a modified Melloy flame photometric detector which measures the emission from $S_{2}$ that originates from a pre-mixed hydrogen-air flame. The $\mathrm{H}_{2}$ was doped with $\mathrm{SF}_{6}$ to linearize the output and to improve the detection limit. In principle the flame photometric detector measures all the $S$ that reaches the flame; furthermore, it is known to be sensitive to humidity and altitude. A full description of the instrument itself, the calibrations and the aircraft tests to which it was subjected are given in Luria et al. (1987). Precision and accuracy values are not cited.

\section{INTERCOMPARISON}

To compare data sets it is desirable to have concentration measurements over identical time intervals. The ground-level AES filters were exposed for 24-h periods commencing daily at $1000 \mathrm{~h}$. The UMD:UW filters followed this pattern during events but ran for several days between events. Therefore, in comparing filter results only the single-day filters with the same start and stop times have been included. Data from the real-time instrumentation at Lewes were reported as $\frac{1}{2}-h$ averages. For intercomparison these data were 
Table 2. Ratios between independent measurements

\begin{tabular}{|c|c|c|c|c|c|c|c|c|c|}
\hline \multirow[b]{3}{*}{ Species } & \multirow[b]{3}{*}{ Location } & \multirow{2}{*}{\multicolumn{4}{|c|}{ UMD:UW/AES }} & \multirow{2}{*}{\multicolumn{3}{|c|}{ Others }} & \multirow{3}{*}{$\begin{array}{l}\text { Mean and S.D. of concentrations } \\
\text { for intercomparison measurements } \\
\qquad\left(\mathrm{n} \mathrm{mol} \mathrm{m} \mathbf{m}^{-3}\right)\end{array}$} \\
\hline & & & & & & & & & \\
\hline & & Mean & S.D. & Accuracy & No. of points & Mean & Accuracy & No. of points & \\
\hline \multirow[t]{3}{*}{ Particulate sulphate } & Lewes & 1.02 & 0.31 & 0.28 & 7 & & & & $44.5 \pm 20.1$ \\
\hline & Bermuda & 0.82 & 0.11 & 0.23 & 4 & & & & $43.4 \pm 17.6$ \\
\hline & Aircraft & 0.71 & 0.13 & 0.20 & 14 & & & & $30.0 \pm 24.4$ \\
\hline \multirow[t]{3}{*}{ Particulate nitrate } & Lewes & 0.64 & 0.31 & 0.18 & 7 & & & & $24.3 \pm 12.7$ \\
\hline & Bermuda & 0.87 & 0.62 & 0.24 & 5 & & & & $16.2 \pm 9.3$ \\
\hline & Aircraft & 2.72 & 1.55 & 0.76 & 13 & & & & $8.0 \pm 8.0$ \\
\hline \multirow{5}{*}{ Sulphur dioxide } & Lewes (ALL) & 0.84 & 0.34 & 0.24 & 8 & & & & $212.6+112.5$ \\
\hline & (PGAA) & 0.91 & 0.34 & 0.25 & 5 & $\begin{array}{cr}1.2 & 0.36 \\
(\mathrm{PGAA} / \mathrm{IC})\end{array}$ & 0.33 & 3 & $246.2 \pm 116.1$ \\
\hline & (IC) & 0.72 & 0.29 & 0.20 & 3 & & & & $152.6 \pm 70.7$ \\
\hline & Bermuda & 0.59 & 0.16 & 0.17 & 2 & & & & $5.9 \pm 4.5$ \\
\hline & Aircraft & & & & & $\begin{array}{cc}2.0 & 1.2 \\
(\mathrm{AES} / \mathrm{NOAA})\end{array}$ & 0.73 & 5 & $73.6 \pm 64$ \\
\hline \multirow[t]{3}{*}{ Nitric acid } & Lewes & 0.96 & 0.44 & 0.27 & 4 & & & & $38.1 \pm 17.1$ \\
\hline & & & & & & $\begin{array}{cc}1.24 & 0.31 \\
\text { (AES/YORK) }\end{array}$ & 0.35 & 4 & $29.6 \pm 14.4$ \\
\hline & Bermuda & 0.66 & 0.46 & 0.18 & 5 & & & & $2.4 \pm 2.2$ \\
\hline
\end{tabular}


averaged over the 24-h period to match the filter collection period. On the aircraft, filters were collected at a single altitude, or sometimes at two altitudes if the legs were both either above or below the boundary layer. In each case the filter-packs from the two groups were changed simultaneously. Unlike at the groundbased stations, the aircraft sampling period was highly variable. The real-time $S$ analyzer gave a data point each min; these values were averaged to coincide exactly with a filter collection period.

We have further grouped the data set by site to identify any location-specific field-sampling, or sample-handling problems.

To compare the different measurement techniques we have determined the ratios of the independently determined concentrations. Table 2 gives the averages of these ratios, their standard deviations and the number of points used in each determination. The stated accuracy of the ratio was determined from the accuracies claimed for each group's measurements, assuming the errors to be independent. The mean and standard deviation of the concentration measurements used (both systems) indicate the range of average concentrations over which the intercomparison was made. The ratios should be within the accuracy of unity. The scatter, as measured by the standard deviation of the mean of the ratios, is a measure of the
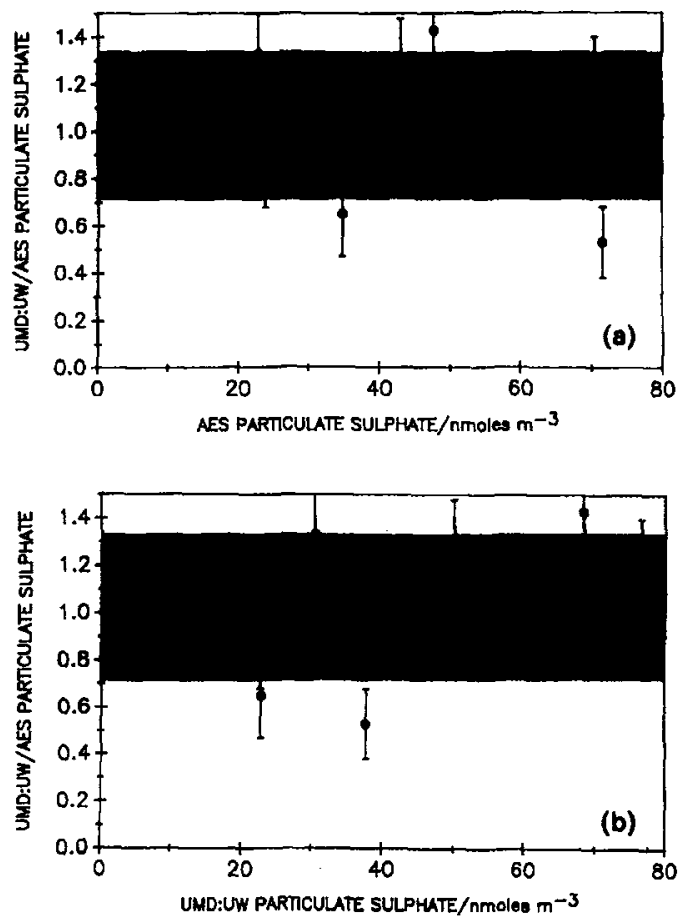

Fig. 1. The ratio between the UMD:UW and AES particulate sulphate measurements at Lewes, Delaware, as a function of the AES measurement (a) and the UMD:UW measurement (b). Error bars are obtained from investigators' accuracy estimates. The shaded areas represent the mean of the measurements \pm one standard deviation. precision of the measurements and the deviation from unity a measure of differences in accuracy. Plots of the ratio against each group's measured concentration were made for each location and for the combined data set to test for a concentration bias between pairs of measurement techniques (cf. Figs 1 and 2).

The agreement between the UMD:UW to AES sulphate measurements at Lewes and Bermuda is good, but a significantly weaker agreement exists for the aircraft measurements.

At Lewes the mean ratio of the UMD:UW to AES measurements (Table 2), is 1.02 and well within the measurement accuracy of unity. There is no correlation between the ratio and the absolute concentration even though the concentration changed by almost a factor of 4 [see Figs 1(a) and (b)]. In Bermuda the four ratios average 0.82 , again within the measurement accuracy of unity. Since there are only four points we cannot say anything about any variation in this ratio with concentration. The ratio of the UMD: UW to AES measurements on the aircraft vary from 0.5 to 1.0 with a mean of 0.71 . This average is not within the measurement accuracy of unity, indicating a problem with some of the aircraft $\mathrm{SO}_{4}^{2-}$ measurements. There is no concentration dependence on this ratio [Figs $2(a)$ and (b)]. The average concentrations measured at the three sites are similar but, as the collection times
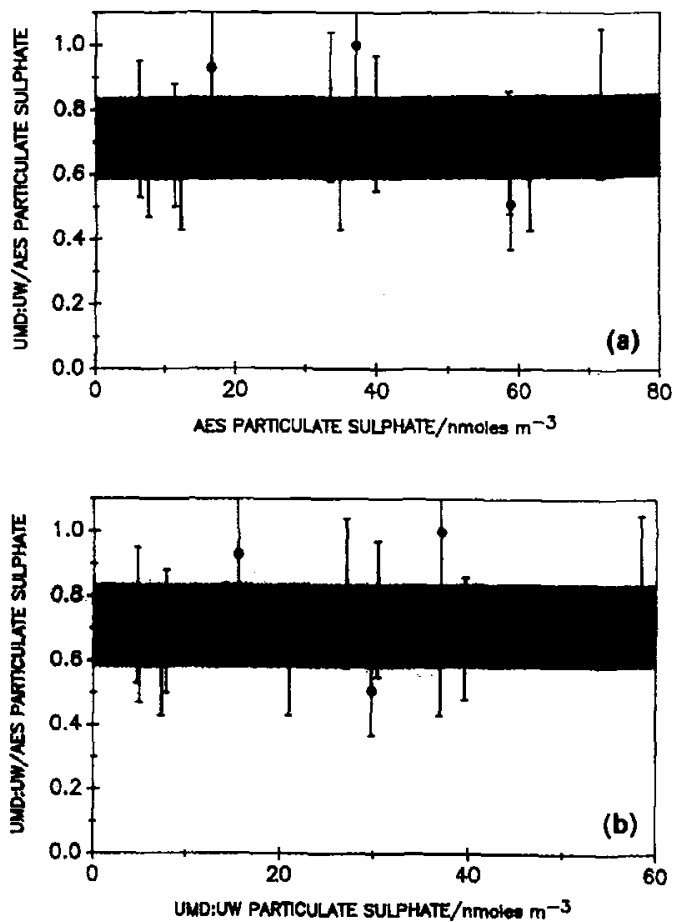

Fig. 2. The ratio between the UMD:UW and AES particulate sulphate measurements on the aircraft as a function of the AES measurement (a) and the UMD:UW measurement (b). Error bars are obtained from investigators' accuracy estimates. The shaded areas represent the mean of the measurements \pm one standard deviation. 
on the aircraft were much shorter, only $1 / 10$ the $\mathrm{SO}_{4}^{2-}$ was collected on the aircraft samples, compared to the ground samples. The difference between the groundbased and aircraft intercomparisons could be due to difficulties in handling filters on the aircraft or a greater uncertainty in determining the lower amounts of material.

In light of the good intercomparison, and in the absence of a direct measurement, we see, for $\mathrm{SO}_{4}^{2-}$ measurements, that the investigators' stated accuracies of $20 \%$ are consistent with the data for the ground-based measurements. However, due to handling problems and/or lower sample weights, the measurement precision (and, perhaps, the accuracies) are underestimated for the aircraft measurements. If the problem is with only one of the two groups then we estimate the accuracy of averaged $\mathrm{SO}_{4}^{2-}$ measurements to be no better than $28 \%$.

The $\mathrm{NO}_{3}^{-}$intercomparison between UMD:UW and AES show greater deviations than observed for $\mathrm{SO}_{4}^{2-}$.

At Lewes the ratio, UMD: UW to AES, is more than one standard deviation below unity, and while this is significant only at the $5 \%$ level, the fact that the range is from 0.33 to 1.24 and only one value of 7 exceeds unity gives cause for concern. This is a case where the small number of measurements limits the conclusions of the intercomparison. There is a weak correlation of the ratio with the UMD:UW concentration (Fig. 3) (but not with the AES concentration). A least-squares fit gives the ratio as $(0.021 \pm 0.007)$ (concentration) $+(0.24 \pm 0.21)$ with a 0.82 correlation coefficient for the seven points. Figure 3 shows the best-fit line with the extremes of the fitting parameters as well as the mean and standard deviation of the data points. With the large scatter in the data it is not clear that one method of data treatment is preferable. We have chosen to describe the $\mathrm{NO}_{3}^{-}$data at Lewes by the

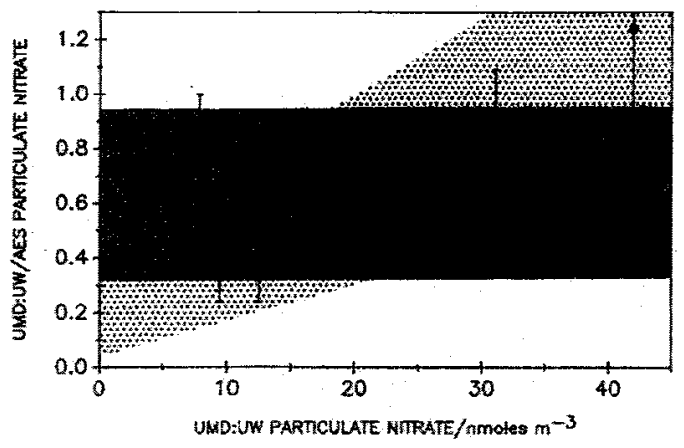

Fig. 3. The ratio between the UMD:UW and AES particulate nitrate measurements at Lewes, Delaware, as a function of the UMD:UW measurement. Shown are the data points, with error bars determined from the investigators' accuracy estimates. The horizontal shaded area gives the mean \pm one standard deviation. The sloping shaded area gives the range of values obtained from a least. squares fit to the data. mean and standard deviation. The two groups" $\mathrm{NO}_{3}^{-}$ measurements can be averaged but the average can have an accuracy of no better than $28 \%$ since no independent $\mathrm{NO}_{3}^{-}$measurements are available.

At Bermuda the ratio of UMD:UW measurements to AES measurements is within the measurement accuracy of unity although the range of values is from 0.24 to 2.02 and the standard deviation is $70 \%$ of the mean. Since there are only five points a correlation of this ratio with concentration is not possible. These data would justify using the cited $20 \%$ accuracies, but in light of the range of values and the Lewes results, estimated accuracy of $28 \%$ is more realistic. Combination of the data sets from Lewes and Bermuda provided no new insight into the possible source of these weak intercomparisons.

The ratio of UMD:UW to AES nitrate measurements from the aircraft, 2.72 with a standard deviation of 1.55 , is not within one standard deviation of unity. There are 13 points in this intercomparison ranging in value from 6.01 to 0.98 , of which only one is below unity indicating a strong bias in the data. The same techniques and laboratories were used on filters from all sites, minimizing differences due to analysis techniques, although, as with $\mathrm{SO}_{4}^{2-}$, the mass of sample from aircraft filters is much less than that from ground sites. We must conclude that there are problems associated with either the sampling system on the aircraft, the way in which the filters were handled on the aircraft, or an overestimate of the detection limit of the technique, and that the individual measurements are suspect. Since the averages generally agree better than the individual values, averaging the two groups' data together is still justified but the accuracy of the averages is no better than $60 \%$.

The $\mathrm{SO}_{2}$ intercomparison between the filter techniques at the ground sites was very good, but no conclusions could be drawn from the comparison between one of the filters and the real-time analyzer.

A number of intercomparisons are possible. First, there is the intercomparison between the PGAA and IC analyses used for the UMD:UW filters. This is especially important as neither analytical technique was used on all samples. Intercomparisons are then possible between the AES and UMD:UW filter data at the ground sites, and between the AES filter pack data and the real time data from the aircraft.

Only three samples were analyzed for $S$ by both PGAA and IC. The ratios of these results (Table 2) show that on average there is no significant difference between the two techniques. The ratio of the UMD:UW data and the AES data, which were analysed by IC was then determined. The PGAA and the IC data separately and the total UMD:UW data ratioed to the AES data again, for the averages, show no significant difference from unity, although individual values of the ratio ranged from 0.3 to 1.3 . The average of the two points from Bermuda lie within one standard deviation of the Lewes mean. We conclude that all three systems give equivalent measurements of 
$\mathrm{SO}_{2}$ and that the investigators' quoted $20 \%$ accuracies are consistent with the data over the concentration range encountered.

We were unable to obtain a satisfactory intercomparison between the real-time analyzer and the AES filter-pack system on the aircraft. There were only a limited number of filters for which the $\mathrm{SO}_{2}$ concentrations were thought to be reliable. Even with this set the comparison was only within a factor of two. In light of the good intercomparison between the filter systems we prefer not to combine the data from the two systems on the aircraft.

There is very good agreement between the UMD:UW and AES filter-pack $\mathrm{HNO}_{3}$ measurements and between the AES and Tunable Diode Laser measurements.

Intercomparisons of the $\mathrm{HNO}_{3}$ results are possible between the filter techniques at the two ground stations, and between the TDLAS and the filter systems at Lewes. The ratios between the two filter-pack systems are within a standard deviation of unity even though the absolute concentrations differ by a factor of 16 between the two sites. Due to the lack of overlapping data we have only compared the TDLAS $\mathrm{HNO}_{3}$ data with those of the AES filter system. There is no significant difference between the results of the two techniques. There is no evidence for a trend in the ratio of any pair of measurements with measured concentration. The investigators' quoted accuracies are consistent with the data and since the TDLAS is a specific method for unambiguously measuring $\mathrm{HNO}_{3}$ (Hastie et al., 1983), we believe the $\mathrm{HNO}_{3}$ data set to be of high quality.

\section{CONCLUSIONS}

The $\mathrm{N}$ and $\mathrm{S}$ compound measurements made during WATOX-85 have been examined to assess their suitability in determining the flux and fate of $S$ and $N$ advected eastward from North America.

Through technique intercomparison we were able to check the consistency of the investigators' accuracy estimates, and in cases where the intercomparison showed differences, to place more realistic accuracy estimates on the data. Results of the intercomparison are consistent with the investigators' claimed accuracies of $20 \%$ for all the ground-based particulate $\mathrm{SO}_{4}^{2-}$, all the filter $\mathrm{SO}_{2}$ and $\mathrm{HNO}_{3}$ measurements. The intercomparison showed that the ground-based particulate $\mathrm{NO}_{3}^{-}$and aircraft particulate $\mathrm{SO}_{4}^{2-}$ were less accurate and the accuracies of these measurements are estimated to be no better than $28 \%$. The aircraft particulate nitrate measurements have a poor intercomparison and the accuracy is believed to be no better than $60 \%$. $\mathrm{A} \mathrm{SO}_{2}$ intercomparison between the real-time analyzer and a filter system on the aircraft was inconclusive and we make no recommendations regarding the aircraft $\mathrm{SO}_{2}$ measurements.

Acknowledgements-This work was supported by the Atmospheric Environment Service of Environment Canada, the Ontario Ministry of the Environment, the National Sceinces and Engineering Research Council, and the National Oceanic and Atmospheric Administration. We gratefully acknowledge the able assistance of J. Scudlark and P. Salevin who operated the field site at Lewes, and of R. Sherriff-Dow who operated the Bermuda site. We also acknowledge the contributions to data acquisition and analysis of $G$. I Mackay, G. W. Harris, M. N. Stevenson, J. F. O'Loughlin, L. McCarthy, M. Kitto, D. Wellman, L. Gunter, J. Boatman, S. Barzetti, S. Symington and S. Melnichuk.

This is contribution No. 1158 of the Bermuda Biological Station and a contribution to the Western Atlantic Ocean Experiment.

\section{REFERENCES}

Anlauf K. G., Fellin P., Wiebe H. A., Schiff H. I., Mackay G. I., Braman R. S. and Gilbert R. (1985) Methods for measurement of atmospheric nitric acid and aerosol nitrate and ammonium. Atmospheric Environment 19, 325-333.

Fehsenfeld F. C., Dickerson R. R., Hübler G., Luke W. T. Nunnermacker L. J., Williams E. J., Roberts J. M., Calvert J. G., Curran C. M., Delany A. C., Eubank C. S., Fahey D. W., Fried A., Gandrud B., Langford A. O., Murphy P. C., Norton R. B., Pickering K. E. and Ridley B. A. (1987) A ground-based intercomparison of $\mathrm{NO}, \mathrm{NO}_{x}$ and NO, measurement techniques. J. geophys. Res. 92, $14,710-14,722$.

Germani M. S., Gokmen I. Sigleo A. C., Kowalczyk G. S., Olmez I., Small A. M., Anderson D. L., Falley M. P. Gulovali M. C., Choquette C. E., Lepel E. A., Gordon G. E. and Zoller W. H. (1980) Concentrations of elements in the National Bureau of Standards' Bituminous and Subbituminous Coal Standard Reference Materials. Analyt. Chem. 52, 240-245.

Hastie D. R., Mackay G. I., Iguchi T., Ridley B. A. and Schiff H. I. (1983) Tunable diode laser systems for measuring trace gases in tropospheric air. Envir. Sci. Technol. 17. 352A-364A.

Kitto M. E., Anderson D. L. and Zoller W. H. (1988) Simultaneous collection of particles and gases followed by multielement analyses using nuclear techniques. J. Atmos. Chem. (accepted for publication).

Luria M., Van Valen C. C., Boatman J. F., Wellman D. L. and Pueschel R. F. (1987) Sulphur dioxide flux measurements over the western Atlantic Ocean. Atmospheric Environment 21, 1631.

Misanchuk B. A., Hastie D. R. and Schiff H. I. (1988) The distribution of nitrogen oxides off the east coast of North America Global Biogeochem. Cycles 1, 345.

Wolff G. T., Kelley N. A., Ferman M. A., Ruthkosky M. S., Stroup D. P. and Korsog P. E. (1986) Measurements of sulphur dioxide, nitrogen oxide, haze and fine particles at a rural site on the Atlantic Coast. J. Air Pollut. Control Ass. 36, 585-591. 